\title{
Neurons of the Myenteric Plexus of the Rat Ileum Are Vulnerable to the Action of the Herbicide 2,4-Dichlorophenoxyacetic Acid
}

\author{
Ricardo de Melo Germano (Corresponding Author) \\ Postgraduate Program in Animal Science with Emphasis on Bioactive Products - \\ Universidade Paranaense, UNIPAR \\ Praça Mascarenhas de Moraes, 4282, Umuarama/PR \\ Tel: (44) 3621-2828 E-mail: prof.ricardogermano@gmail.com
}

\begin{abstract}
Renata de Britto Mari
Animal Morphophysiology Research Laboratory - Institute of Biosciences at Universidade Estadual Paulista, UNESP - Câmpus do Litoral Paulista

Praça Infante Dom Henrique s/n. São Vicente/SP

Tel: (55) 133569-7100 E-mail: renatamari@gmail.com
\end{abstract}

\begin{abstract}
Paula Montanhini Favetta
Postgraduate Program in Animal Science with Emphasis on Bioactive Products Universidade Paranaense, UNIPAR

Praça Mascarenhas de Moraes, 4282, Umuarama/PR

Tel: (44) 3621-2828 E-mail: nutripaulafavetta@gmail.com
\end{abstract}

\begin{abstract}
Marcelo Alberto Elias
Postgraduate Program in Animal Science with Emphasis on Bioactive Products Universidade Paranaense, UNIPAR and Professor at the Federal Institute of Paraná

Praça Mascarenhas de Moraes, 4282, Umuarama/PR
\end{abstract}

Tel: (44) 3621-2828 E-mail: marcelo.elias@ifpr.edu.br 
Wesley Alves Trindade

Postgraduate Program in Animal Science with Emphasis on Bioactive Products Universidade Paranaense, UNIPAR

Praça Mascarenhas de Moraes, 4282, Umuarama/PR

Tel: (44) 3621-2828 E-mail: wesleyalvest@gmail.com

\title{
Gabriela Pustiglione Marinsek
}

Postgraduate Program in Biodiversity of Coastal Environments - Universidade Estadual Paulista, UNESP - Câmpus do Litoral Paulista

Praça Infante Dom Henrique s/n. São Vicente/SP

Tel: (55) 133569-7100 E-mail: gabriela.marinsek@unesp.br

\author{
Marcílio Hübner de Miranda-Neto \\ Department of Morphological Sciences - Universidade Estadual de Maringá, UEM \\ Avenida Colombo, 5790, Maringá/PR
}

Tel: (44) 3011-4040 E-mail: mhmneto@uem.br

Received: Sep. 29, 2020

doi:10.5296/jas.v9i1.17758
Accepted: Nov. 5, $2020 \quad$ Published: Nov. 9, 2020

URL: https://doi.org/10.5296/jas.v9i1.17758 


\section{Graphic abstract}<smiles>CC(Oc1ccc(Cl)cc1Cl)C(=O)O</smiles>
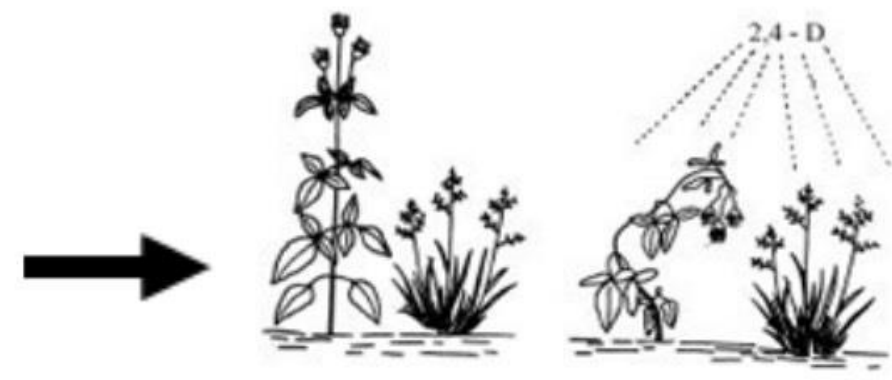

Effect of 2.4 D on agriculture -

leaf epinasty

Chemical structure of $2,4 \mathrm{D}$

Source: encurtador.com.br/emoNP


Effect on ileum neurons -

atrophy of excitatory and

hyperophy of inhibitors.

\section{Abstract}

The herbicide 2,4-dichlorophenoxyacetic acid $(2,4-\mathrm{D})$ is widely used in several countries. Research on the neurotoxicity of 2,4-D has been focused on the central nervous system, and little is known about its effects on the myenteric plexus. Therefore, to elucidate the neurotoxicity of 2,4-D and the viability of its use, we investigated the effects of daily intake of $5 \mathrm{mg} 2,4-\mathrm{D} / \mathrm{kg}$ for 60 days on the myenteric plexus neurons of the rat ileum using quantitative and morphometric analyses. Twenty male Wistar rats aged 60 days were divided into two groups ( $\mathrm{n}=10 \mathrm{rats} /$ group). The group $\mathrm{E}$ animals received daily $5 \mathrm{mg}$ doses of 2,4-D/kg diluted in $1 \mathrm{~mL}$ of water, whereas the group $\mathrm{C}$ animals were not treated with the herbicide. The animals were euthanized with anesthetic after 60 days; subsequently, the ileum was dissected out, and procedures were performed to visualize the total population of neurons (Giemsa staining), the nitrergic neurons (NADPHd+), and the estimated population of cholinergic neurons (NADPHd-). The results were statistically analyzed and compared between groups. In group E, the densities of Giemsa-stained neurons and NADPHd- neurons decreased $(\mathrm{p}<0.05)$ by $7 \%$ and $10 \%$, respectively, whereas the density of NADPHd+ neurons remained constant. The cell body area was $5.8 \%$ greater $(\mathrm{p}<0.05)$ for the NADPHd+ neurons but remained unchanged for the neurons stained with Giemsa. These results suggest that 
2,4-D causes a reduction in neuronal density, particularly for cholinergic neurons, and promotes an increase in the cell body area of nitrergic neurons, leading to hypertrophy.

Keywords: 2-4-D, intestine, herbicide, enteric nervous system

\section{Introduction}

The herbicide 2,4-dichlorophenoxyacetic acid (2,4-D) is used in agriculture, parks, and gardens to eliminate weeds and can cause intoxication in humans as well as other animals (Margonato et al. 2003).

The contamination of humans and other animals by 2,4-D can occur during its transportation, storage, handling for preparation and application, as well as by the inhalation of, contact with, and ingestion of contaminated air, water, and food (Aydin et al. 2005, Bolognesi 2003).

The toxic dose of ingested 2,4-D for humans is approximately 3-4 g, and the lethal dose is 28 $\mathrm{g}$ (Tsman 1991). For rats, the lethal dose is $375 \mathrm{mg} / \mathrm{kg}$ body weight (Almeida \& Rodrigues 1988). Neurotoxicity is the predominant effect of its oral ingestion and inhalation (Mattson et al. 1997; Schvartsman 1991, Epa 1987). However, digestive complications, chest and abdominal pain, breathing difficulties, and muscle problems, such as asthenia, have also been reported (Abdollahi, 2004, Charles et al. 1996a, 1996b).

Several studies have been conducted to elucidate the mechanisms of the action of 2,4-D in various animal systems, and neurotoxicity studies have focused on the central nervous system (Bjorling-Poulsen et al. 2008, Konjuh et al. 2008, Bongiovanni et al. 2007).

The mechanisms proposed for the neurotoxicity of 2,4-D include inhibition of organic acid transport out of the brain, leading to high levels of metabolites from the biogenesis of amines (Elo \& MacDonald, 1989); inhibition of microtubule polymerization (Rosso et al. 2000); production of free radicals (Bongiovanni et al. 2007, Bjorling-Poulsen et al. 2008, Bukowska et al. 2008); decreased levels of reduced glutathione (Bukowska 2003) and impairments of antioxidant enzymes, such as superoxide dismutase and catalase (Bukowska et al. 2008a, 2008b, Bongiovanni et al. 2007, Bukowska 2003); changes in neuron cell membranes with an uncoupling of the oxidative phosphorylation and disruption of the metabolism of acetyl coenzyme A (Bradberry et al. 2000); and covalent modifications that affect the protein structure (Di Paolo et al. 2001).

Changes in the functional and structural integrity of proteins in the plasma membrane and organelles can trigger changes in the energy metabolism that affects the biological activities of cells, such as ATP synthesis, signaling, regulation of biosynthesis and catabolic reactions and transport of metabolites and ions, and can compromise cellular integrity (Palmeira et al. 1997).

Only a few studies have focused on the effects of 2,4-D on the peripheral nervous system, including the enteric nervous system (ENS). Among the constituents of the ENS is the myenteric plexus, which-along with other ENS neurons-responds to various types of stimuli and conditions - deleterious or not-by changing their chemical or functional structure to maintain the homeostasis of the digestive system (Lomax et al. 2005). 
Conditions that cause functional damage to the digestive tract have been induced in vivo to analyze the myenteric plexus. Morphometric and quantitative parameters of myenteric neurons were analyzed in Parkinson's disease, Crohn's disease, toxoplasmosis (Hermes-Uliana et al. 2011, Anderson et al. 2007, Boyer et al. 2007), malnutrition and during caloric or protein restriction (Sant'Ana et al. 2012, Silva-Porto et al. 2012; Natali et al. 2005, 2003, Cowen et al. 2000), diabetes (Fregonesi et al. 2005, Zanoni et al. 2003), and during aging (Gagliardo et al. 2008, Mari et al. 2008, Marese et al. 2007, Phillips et al. 2003), among other conditions.

These studies have revealed neuronal preservation or hyper- or hypoplasia with or without atrophy or hypertrophy of the cell bodies of the total neuronal population and subpopulations. However, the results were associated with the type and severity of the condition and the segment of the digestive tract that was analyzed.

Correa et al. (2011) reported that the daily intake of $5 \mathrm{mg}$ of 2,4-D/kg/15 days interfered with myenteric neuronal plasticity in the rat jejunum by promoting hypertrophy of the nitrergic neurons without changing the total neuronal population density.

The myenteric plexus is located in the muscular wall of the digestive tract and consists of neurons grouped into a network of nodes of various sizes and shapes, where different neurons express different neurotransmitters (Furness, 2006; Furness \& Costa 1987).

Because of this and the fact that 2,4-D is rapidly and well absorbed from the intestine, the signs of intoxication by 2,4-D include digestive complications, such as nausea, vomiting, diarrhea, acute gastritis, and abdominal pain (Charles et al. 1996a, 1996b); thus, it would be expected that the intake of this drug could interfere with or compromise the ENS, even before affecting other organs. However, little is known about the action of this herbicide in the ENS, and there is a need for additional studies on 2,4-D.

The goal of the present study was to investigate the effects of daily intake of $5 \mathrm{mg}$ of $2,4-\mathrm{D} / \mathrm{kg} / 60$ days on neurons of the myenteric plexus of the rat ileum using quantitative and morphometric analysis. The results increase the knowledge regarding the effects of 2,4- D and also support further study to verify and revise the feasibility of the use of this herbicide.

\section{Method}

\subsection{Ethics Committee}

Allthe procedures outlined in this study are consistent with the ethical principles adopted by the Brazilian College of Animal Experimentation (Colégio Brasileiro de Experimentação Animal - COBEA) and were reviewed and approved by the Animal Research Ethics Committee of the State University of Maringá (Universidade Estadual de Maringá - UEM) (Protocol 034/2011).

\subsection{Experimenting Animals}

Twenty male Wistar rats (Rattus norvegicus) from the Central Animal Vivarium at UEM were used. Sixty-day-old rats were kept for 60 days in individual polypropylene rodent cages in a 
room with a controlled photoperiod (12-h light/12-h dark) and temperature $\left(22^{\circ} \mathrm{C} \pm 2^{\circ} \mathrm{C}\right)$.

\subsection{Experimental Design}

The rats received food (Nuvital ${ }^{\circledR}$ lab chow) and water ad libitum and were randomly distributed into two groups ( $\mathrm{n}=10$ rats/group).

For 60 days, the rats in the experimental group (group E) were administered $5 \mathrm{mg} / \mathrm{kg}$ body weight/day of 2,4-D in sodium salt form (Sigma, Steinhein, Germany) diluted in $1 \mathrm{~mL}$ of distilled water by gavage. The rats in the control group (group C) were given $1 \mathrm{~mL}$ of vehicle (distilled water without 2,4-D) by gavage over the same period of time. Their body weights were measured daily to adjust the 2,4-D dose and to determine weight gain during the experimental period.

After the experimental period of 60 days and 12 hours of fasting, the rats were anesthetized by isoflurane inhalation (Vetflurano ${ }^{\circledR}$ ) and euthanized by overexposure to the anesthetic (Hecker et al. 1983). A ventral midline laparotomy was performed on each rat, and the ileum was removed, with the beginning of the ileocecal fold serving as the oral limit and the ileocecal junction as the caudal limit (Greene 1963). Each ileum was outlined in white paper. The drawings were scanned into the computer and the area $\left(\mathrm{mm}^{2}\right)$ of the ileum was determined via image analysis. Subsequently, the ileum was processed to visualize the myenteric neurons, as described below.

\subsection{Basic Giemsa Stain - Detection of the Total Myenteric Neuron Population}

To estimate the total population of myenteric neurons, dyes based on methylene blue (Giemsa staining technique) can be used because they have an affinity for the acid structures of the cell, including the endoplasmic reticulum and the free ribosomes, which are present in all neurons (Nissl's corpuscles) (Silva Porto et al. 2012, Correa et al. 2011, Hermes-Uliana et al. 2011, Marese et al. 2007, Soares et al. 2006, Natali et al. 2005, 2003, Natali \& Miranda-Neto 1996). Therefore, the ilea obtained from 10 rats (five in each group) were washed with $0.9 \%$ saline solution, filled and immersed in Giemsa fixative solution $(30 \mathrm{~mL}$ formaldehyde, $15 \mathrm{~mL}$ acetic acid, $9 \mathrm{~g}$ sodium chloride, and $55 \mathrm{~mL}$ distilled water) for at least 48 hours. To maintain the contents of the ileum, each end was sutured.

After fixation, the sutures were removed, and the ilea were sectioned along the longitudinal axis at the mesenteric insertion. Each ileum was carefully microdissected under a stereomicroscope using trans-illumination to remove the mucosal and submucosal layers. The serosa and muscular layers containing the myenteric plexus were preserved to form the whole mount. Each whole mount (one per ileum) was immersed in the Giemsa stain solution containing methylene blue in Sorensen phosphate buffer ( $\mathrm{pH}$ 6.9) for at least 12 hours at room temperature. The preparations were then dehydrated in ethanol (90\%, 95\%, and 100\%), diaphanized by three dips in xylene, and mounted onto glass slides using Permount $\AA$ synthetic resin.

\subsection{NADPH-diaphorase histochemistry - Detection of NADPH-diaphorase Positive Myenteric Neurons (NADPH-d + neurons)}

Neurons that express nitric oxide (NO) can be visualized using nicotinamide adenine 
dinucleotide phosphate diaphorase (NADPH-diaphorase) histochemistry, following the methods of Scherer-Singler et al. (1983). Approximately 34\% of the total population of myenteric neurons are NADPH-diaphorase-positive (Wester, O’Briain \& Puri et al. 1999).

Therefore, to identify the nitrergic myenteric neurons (NADPHd+ neurons), the ilea obtained from the other 10 rats (5 per group) were washed and filled with phosphate buffer ( $\mathrm{pH} 7.4$ ). The ends of the segments were sutured to retain the filling solution. The segment was washed twice (10 minutes each) in PBS and permeabilized in PBS containing 0.3\% Triton X-100 diluted in sodium phosphate buffer ( $\mathrm{pH} 7.3)$ for 10 minutes.

After permeabilization, each ileum was washed twice (10 minutes each) in PBS and incubated for 120 minutes in a reaction medium containing $50 \mathrm{mg}$ Nitro Blue Tetrazolium (NBT), $100 \mathrm{mg} \beta$-NADPH, and 0.3\% Triton X-100 in Tris- $\mathrm{HCl}$ buffer (0.1 M, pH 7.6). The ends were later released, and the ilea were immersed in $4 \%$ paraformaldehyde for fixation and storage. The fixative solution stopped the reaction.

Subsequently, each ileum was sectioned along the longitudinal axis at the level of the mesenteric insertion, microdissected, dehydrated, diaphanized, and mounted onto glass slides, as previously described for the Giemsa staining procedure.

\subsection{Obtaining Membrane Preparations and Photomicroscopy}

Whole mount obtained from the rat ilea of groups $\mathrm{C}$ and $\mathrm{E}$ were used to quantify the total neuronal population (Giemsa-stained neurons) and the NADPHd+ subpopulation (nitrergic neurons). Each whole mount was visualized under an Olympus light microscope at 400x magnification. The images were captured using a high-resolution digital camera, transferred, and recorded on the computer.

The images were obtained from 120 random microscopic fields per whole mount. The whole circumference of each ileum was sampled, and 600 images per group of each neuronal population were obtained. For each image, all visualized neurons were quantified, and half-visible neurons were counted in alternate fields.

The total area quantified was $11.52 \mathrm{~mm}^{2}$, so the results were expressed as the neuronal density per $\mathrm{mm}^{2}$ of ileum. The difference between the mean of the neuronal density of the total population (Giemsa-stained neurons) and NADPHd+ neurons was used to estimate the population of NADPHd- neurons (cholinergic neurons), according to the methods used by Phillips \& Powley (2007) and Phillips et al. (2003).

Measurements of the cell body area of myenteric neurons were performed using the Image-Pro Plus 3.0.1 image analysis software (Media Cybernetics, Silver Spring, Maryland, USA). For this procedure, images of neurons that had been captured by the digital camera to determine the neuronal density were used. The cell body areas $\left(\mu \mathrm{m}^{2}\right)$ of 100 neurons per whole mount preparation were measured for each animal, totaling 500 neurons per group of each neuronal population. 


\subsection{Statistical Analysis}

Statistical analysis was performed using GraphPad Prism. Initially, the results were analyzed using the Shapiro-Wilk test to determine the type of distribution.

The results were expressed as the mean \pm standard deviation for the data with a normal distribution and as the median and percentiles (P:25 and P:75) for the data with a non-normal distribution. To compare the results between groups $\mathrm{C}$ and $\mathrm{E}$, the data that were normally distributed were subjected to an analysis of variance (one-way ANOVA), followed by Tukey's test. The data with a non-normal distribution were analyzed using the Mann-Whitney test. The significance for all tests was $\mathrm{p}<0.05$.

\section{Results}

There were no behavioral changes in the rats from groups $\mathrm{C}$ and $\mathrm{E}$ and none of the animals died during the experimental period. The initial and final weights of the animals, the weight gain, and the ileum areas $\left(\mathrm{mm}^{2}\right)$ did not differ ( $\left.\mathrm{p}>0.05\right)$ between groups $\mathrm{C}$ and $\mathrm{E}$ (Table 1).

Table 1. Mean and standard deviation of the initial and final body weight (g), weight gain (g) and the area $\left(\mathrm{mm}^{2}\right)$ of the ileum of rats that ingested (group E) or did not ingest (group C) the herbicide 2,4-dichlorophenoxyacetic acid (2,4-D) for 60 days

\begin{tabular}{lcccc}
\hline Group & $\begin{array}{c}\text { Initial } \\
\text { Weight } \\
(\mathbf{g})\end{array}$ & $\begin{array}{c}\text { Final Weight } \\
(\mathbf{g})\end{array}$ & $\begin{array}{c}\text { Weight Gain } \\
(\mathbf{g})\end{array}$ & $\begin{array}{c}\text { Area of the } \\
\text { Ileum } \\
\left(\mathbf{m m}^{\mathbf{2}}\right)\end{array}$ \\
\hline $\mathrm{C}(\mathrm{n}=5)$ & $270.3 \pm 19.1^{\mathrm{a}}$ & $451.8 \pm 56.1^{\mathrm{a}}$ & $177.8 \pm 58.9^{\mathrm{a}}$ & $84.86 \pm 26.28^{\mathrm{a}}$ \\
$\mathrm{E}(\mathrm{n}=5)$ & $266.4 \pm 17.9^{\mathrm{a}}$ & $442.7 \pm 51.8^{\mathrm{a}}$ & $176.4 \pm 52.1^{\mathrm{a}}$ & $91.02 \pm 33.25^{\mathrm{a}}$ \\
\hline
\end{tabular}

Means followed by different letters in the same column are significantly different $(p<0,05)$ using Tukey's test.

Using light microscopy to evaluate the membrane preparations from the ilea of groups $\mathrm{C}$ and $\mathrm{E}$, the myenteric neurons were grouped into ganglia that were interconnected by nerve fiber bundles, and there were no visible arrangement differences between the groups or between the various neuronal populations (Figure 1). 


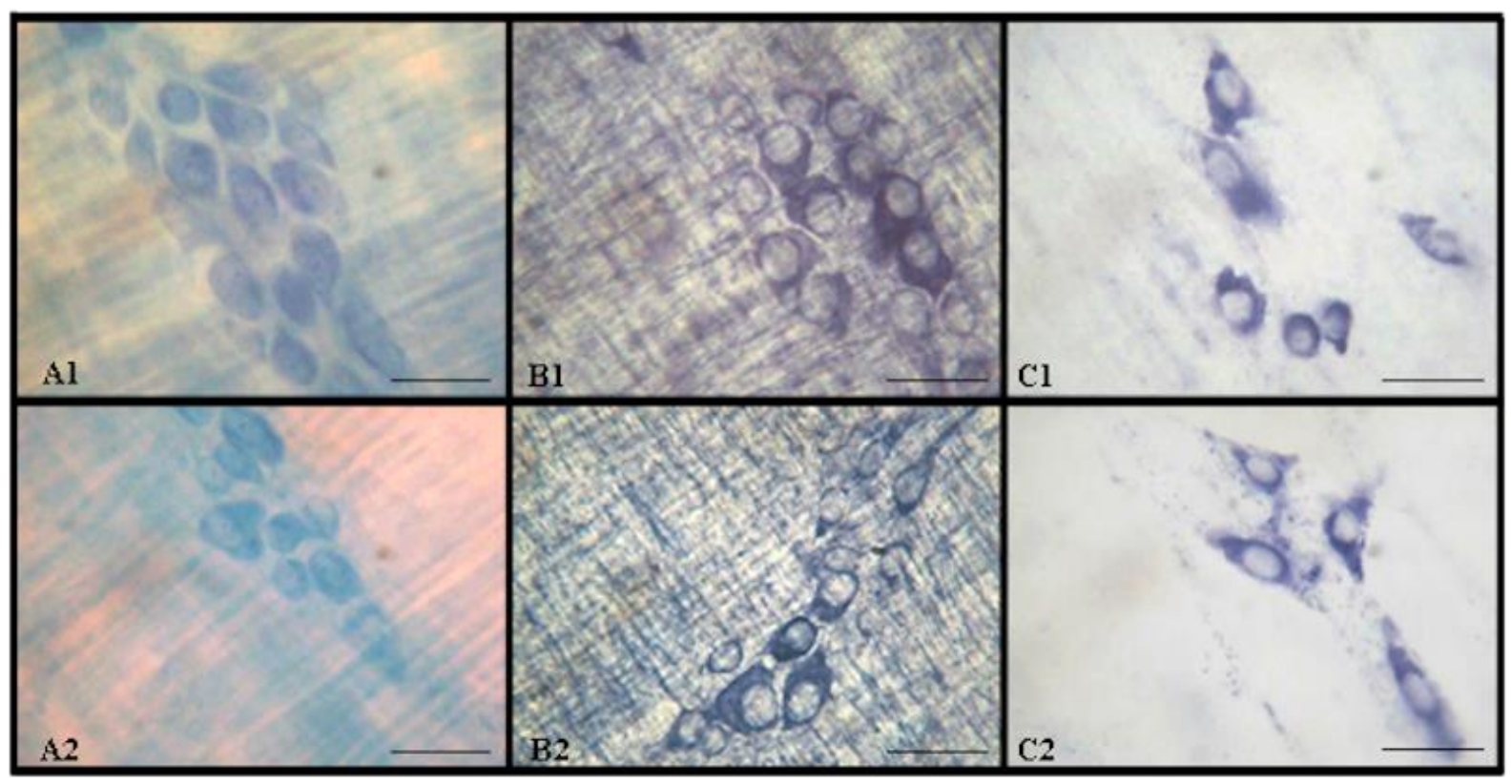

Figure 1. Photomicrographs of membrane preparations of rat ileum, showing myenteric plexus ganglia of the experimental (E1 and E2) and control (C1 and C2) groups. For E1 and

$\mathrm{C} 1$, the ganglia with neurons were revealed by NADPH-diaphorase histochemistry (NADPHd+); for E2 and C2, the neurons were revealed by Giemsa staining (total population of neurons); Bar $=100 \mu \mathrm{m}$

The results of the neuronal density tests obtained from the whole mounts are shown in Table 2. The neuronal density of the total population (Giemsa-stained neurons) was $7 \%$ lower $(\mathrm{p}<0.05)$ in group E $(93.75 \pm 5.1$ neurons $)$ compared to group C $(100.8 \pm 7.8$ neurons $)$ (Table 2$)$.

Regarding the NADPHd+ neurons, the neuronal density did not differ $(p>0.05)$ between groups $\mathrm{C}$ and $\mathrm{E}$ (Table 2). The difference between the density of the total neuronal population and the subpopulation of NADPHd+ neurons was used to estimate the density of cholinergic neurons (NADPHd- neurons), which was $10 \%$ lower $(\mathrm{p}<0.05)$ for group $\mathrm{E}$ than for group $\mathrm{C}$ (Table 2).

Table 2. Mean and standard deviation of the density of myenteric neurons revealed by Giemsa staining (Giemsa), NADPH-diaphorase histochemistry (NADPHd+ neurons), and the estimated cholinergic neurons (NADPHd- neurons) of the ileum of rats that ingested (group E) or did not ingest (group C) the herbicide 2,4-dichlorophenoxyacetic acid (2,4-D) for 60 days

\begin{tabular}{llll}
\hline & \multicolumn{2}{c}{ Neuronal density $/ \mathbf{m m}^{2}$ of ileum } & \\
\cline { 2 - 4 } Groups & Giemsa & NADPHd+ & NADPHd- \\
\hline $\mathrm{C}(\mathrm{n}=5)$ & $100.08 \pm 7.8^{\mathrm{a}}$ & $39.46 \pm 3.5^{\mathrm{a}}$ & $60.67 \pm 4.8^{\mathrm{a}}$ \\
$\mathrm{E}(\mathrm{n}=5)$ & $93.75 \pm 5.1^{\mathrm{b}}$ & $39.20 \pm 7.8^{\mathrm{a}}$ & $54.59 \pm 4.4^{\mathrm{b}}$ \\
\hline
\end{tabular}


Means followed by different letters in the same column are significantly different $(p<0.05)$ between groups using Tukey's test.

The cell body areas of 500 neurons per group in each neuronal population were measured (Table 3). The cell body area dimensions of neurons in the total population (Giemsa-stained neurons) in group E did not differ ( $>>0.05$ ) from those in group $\mathrm{C}$ (Table 3). Regarding the $\mathrm{NADPHd}+$ neurons, the cell body area was $5.8 \%$ greater $(\mathrm{p}<0.05)$ for group $\mathrm{E}$ compared to group C (Table 3).

Table 3. Median and percentiles (P:25; P:75) of the cell body area $\left(\mu \mathrm{m}^{2}\right)$ of myenteric neurons revealed by Giemsa staining (Giemsa) and NADPH-diaphorase histochemistry (NADPH-d+ neurons) of the ileum of rats that ingested (group E) or did not ingest (group C) the herbicide 2,4-dichlorophenoxyacetic acid (2,4-D)

\section{Neuronal cell body area $\left(\mu \mathrm{m}^{2}\right)$}

\begin{tabular}{ccc} 
Groups & Giemsa & NADPH-d+ \\
\hline $\mathrm{C}(\mathrm{n}=5)$ & $208.2(164.0 ; 223.1)^{\mathrm{a}}$ & $284.6(236.7 ; 339.8)^{\mathrm{a}}$ \\
$\mathrm{E}(\mathrm{n}=5)$ & $247.3(197.0 ; 296.6)^{\mathrm{a}}$ & $301.2(248.7 ; 357.0)^{\mathrm{b}}$
\end{tabular}

Medians followed by different letters in the same column are significantly different $(p<0.05)$ between groups by Mann-Whitney test.

\section{Discussion}

The effects of various doses (single doses or continuous administration) of 2,4-D on the central nervous system and other animal organ systems have been greatly evaluated, though few studies have addressed the effect of 2,4-D on the myenteric plexus. Therefore, we carried out this preliminary and exploratory study to determine the effects of ingesting $5 \mathrm{mg}$ of 2,4-D/kg body weight on the myenteric plexus of the rat ileum. We selected this dose based on a previous study by Correa et al. (2011) that investigated the effects of 2,4-D on the myenteric plexus of the rat jejunum, and the $5 \mathrm{mg}$ dose allowed an appropriate comparison of the results obtained in this study with those reported previously.

Throughout the experimental period (60 days), 2,4-D did not induce behavioral changes or death in the rats. In addition, no effect was observed on the weight of the rats. At the beginning and end of the experiment, the weights of the animals did not differ ( $p>0.05)$ between groups $\mathrm{C}$ and E. Similar results were reported by Correa et al. (2011) with a daily dose of $5 \mathrm{mg}$ 2,4-D/kg for 15 days. In other studies, doses of $15-70 \mathrm{mg} / \mathrm{kg} /$ day of 2,4-D also had no effect on the weight of the rats (Konjuh et al. 2008, Sturtz et al. 2006).

The area of the ileum of the animals from group E did not change compared to group C, indicating that ingestion of 2,4-D for 60 days did not affect the size of the ileum. Therefore, quantitative evaluations of neurons were performed without the need to use a correction 
factor to compensate for changes in the size of the intestinal segment and avoid errors in the determination of neuronal density, as recommended by Phillips \& Powley (2001), Johnson et al. (1998), and Gabella (1989).

Through visualization of the whole mount under light microscopy, it was evident that 2,4-D did not alter the spatial organization of the myenteric plexus. In both groups (E and $C$ ), the neurons were predominantly clustered in ganglia connected with nerve fiber bundles, as also shown by Correa et al. (2011) in the jejunum of rats.

The herbicide ingestion decreased the density of the total neuronal population (Giemsa-stained neurons), which was $7 \%$ smaller $(\mathrm{p}<0.05)$ in group $\mathrm{E}$ than in group $\mathrm{C}$. Regarding the NADPHd+ neurons, their density in group E was not affected ( $p>0.05)$ by the ingestion of 2,4-D and remained similar to that in group $\mathrm{C}$.

In contrast to the current study, Correa et al. (2011) reported that the daily intake of $5 \mathrm{mg}$ of 2,4-D/kg for 15 days did not decrease the density of the neurons stained with Giemsa or the $\mathrm{NADPHd}+$ neurons in the rat jejunum. One potential explanation for this difference in results may be that the longer exposure of animals to 2,4-D (60 days) in the current study resulted in a more severe treatment for the ileum neurons in Group E than with the conditions used (15 days) by Correa et al. (2011). The signs of intoxication by 2,4-D in laboratory animals are dose- and time-dependent (Paulino et al. 1996), and it is therefore expected that the detection of tissue changes are also dose- and time-dependent.

The difference between the density of the total neuronal population (Giemsa staining) and the population of NADPHd+ neurons enables an estimate of the population of NADPHdneurons, which, according to Phillips \& Powley (2007) and Phillips et al. (2003), are cholinergic. The intake of 2,4-D decreased the density of cholinergic neurons (NADPHd-) resulting in a $10 \%$ smaller $(\mathrm{p}<0.05)$ population in group $\mathrm{E}$ than in group $\mathrm{C}$. The lower density of cholinergic neurons in group $\mathrm{E}$ was further reflected by the decrease in total neuronal density (Giemsa-stained neurons).

The change in neuronal density observed with the ingestion of 2,4-D is consistent with the neuronal loss reported under other conditions that compromise the myenteric plexus, such as the increased vulnerability of cholinergic neurons and the greater resistance of nitrergic neurons in response to the deleterious effects of aging (Silva-Porto et al. 2012, Gagliardo et al. 2008, Phillips et al. 2003, Cowen et al. 2000).

Similar to the current study with 2,4-D, nitrergic neurons have been reported to be more resistant to the diabetic conditions that promote cell death (Zanoni et al. 2003, Miranda-Neto et al. 2001, Belai et al. 1995). Therefore, these findings likely explain the observed decrease in cholinergic neuronal density (NADPHd-) and the preservation of nitrergic neuronal density (NADPHd+) in the ilea from group E, thereby revealing the greater vulnerability of cholinergic neurons to $2,4-\mathrm{D}$.

Although an assessment of the mechanisms of action of 2,4-D neurotoxicity was not the goal of the present research, this topic should be discussed as it has been suggested that 2,4-D may possess multifactorial mechanisms of action which could promote neuronal death. However, 
changes that alter the functional and structural integrity of proteins in the plasma membranes and organelles, as reported by Palmeira et al. (1997), Bradberry et al. (2000), and Di Paolo et al. (2001), could compromise the integrity of the cell and lead to neuronal death. It is notable that in the rat cerebellum and erythrocytes, there is also an increase in oxidative stress and free radical production and a decrease in antioxidant enzymes (Bukowska et al. 2008a, 2008b, Bongiovanni et al. 2007, Bukowska 2003); these factors are known to contribute to cell death.

The cell body areas of neurons stained with Giemsa in group E remained similar to those of group C. However, the cell body area was $5.8 \%$ greater $(\mathrm{p}<0.05)$ for the NADPHd+ neurons of the ileum in group E relative to those in group C. Correa et al. (2011) also observed a 5\% increase in the cell body area of NADPHd+ myenteric neurons of the rat jejunum; however, unlike the results observed in the ileum, they found a decrease in the cell body area of the jejunum neurons stained with Giemsa.

The neuronal pattern along the digestive tract is not the same for all segments, and neurons are not affected simultaneously or at the same intensity (Phillips et al. 2003), which may partially explain the differences observed in the cell body areas of Giemsa-stained neurons from the jejunum and ileum under the effects of 2,4-D. The time of exposure to 2,4-D is also a factor to be considered because the actions of 2,4-D are time- and dose-dependent, as previously mentioned by Paulino et al. (1996).

Nevertheless, the hypertrophy observed in NADPHd+ neurons of the ileum from group E can be attributed to an increase in NO production and also to the oxidative stress stimulated by 2,4-D. Although these attributes were not measured in the present study, it is known that the formation of free radicals with the inhibition of reduced glutathione levels and the impairment of antioxidant enzymes, such as superoxide dismutase and catalase, are factors that mediate the neurotoxicity of 2,4-D (Bukowska et al. 2008a, 2008b, Bongiovanni et al. 2007, Bukowska 2003).

During oxidative stress, there is increased utilization of NADPH by the antioxidant enzymes aldose reductase and glutathione reductase (Cameron et al. 1993). Therefore, in NADPHd+ neurons, the availability of NADPH for nitric oxide synthase (NOS) activity would be decreased, which would induce NADPHd+ neurons to stimulate the metabolic pathways of NO synthesis and consequently increase their cell body area (Fregonese et al. 2005, Zanoni et al. 2003).

Furthermore, hypertrophy of the cell body area of NADPHd+ neurons and the NOS neurons has been attributed to oxidative stress (Shotton et al. 2007, Shotton \& Lincoln 2006, Fregonesi et al. 2005, Zanoni et al. 2003), and neurons that use NO have increased protective mechanisms against the deleterious effects of free radicals (Cowen et al. 2000).

Despite numerous studies on the effects of 2,4-D on the central nervous system, the mechanism of its neurotoxicity remains unclear (Bjorling-Poulsen et al. 2008, Konjuh et al. 2008, Bortolozzi et al. 2004). Therefore, more research on the effects of 2,4-D should be pursued, primarily to support activities that review and explore the viability of using this 
herbicide.

The herbicide 2,4-D is rapidly and well absorbed by the intestine (Charles et al. 1996a, 1996b). Therefore, the intramural location of the myenteric plexus may allow more rapid identification of its effects on the nervous system, without the need to excessively increase the dosage or prolong the time of exposure to the herbicide. Hence, the myenteric plexus should be used to study the neurotoxicity of 2,4-D as well as other herbicides, and further research with different dosages and times of exposure to 2,4-D should be conducted to determine the vulnerability of other enteric neuronal populations to 2,4-D.

The results of the present study reveal that the myenteric plexus of the ileum is susceptible to the action of 2,4-D, as the intake of $5 \mathrm{mg} 2,4-\mathrm{D} / \mathrm{kg} /$ day for 60 days decreased neuronal density, especially in cholinergic neurons, and promoted hypertrophy of the cell body area of nitrergic neurons.

\section{Acknowledgments}

This study was supported by the Brazilian National Agency for the Support and Evaluation of Graduate Education (Coordenação de Aperfeiçoamento de Pessoal de Nível Superior CAPES). The authors thank Paranaense University (Universidade Paranaense - UNIPAR) for providing their laboratories for the implementation of parts of this study, as well as providing financial support through a Faculty Enhancement grant to the first author. In memorian Prof. Dr. Sandra Regina Stabille.

\section{References}

Abdollahi, M., Ranjbar, A., Shadnia, S., Nikfar, S., \& Rezaiee, A. (2004). Pesticides and oxidative stress: a review. Medical Science Monitor, 10, 6. RA141-RA147.

Anderson, G., Noorian, A. R., Taylor, G., Anitha, M., Bernhard, D., Srinivasan, S., \& Greene, J. G. (2007). Loss of enteric dopaminergic neurons and associated changes in colon motility in an MPTP mouse model of Parkinson's disease. Experimental neurology, 207, 4-12. https://doi.org/10.1016/j.expneurol.2007.05.010

Aydın, H., Özdemir, N., \& Uzunören, N. (2005). Investigation of the accumulation of 2, 4-dichlorophenoxyacetic acid (2, 4-D) in rat kidneys. Forensic science international, 1531, 53-57. https://doi.org/10.1016/j.forsciint.2005.04.018

Belai, A., Cooper, S., \& Burnstock, G. (1995). Effect of age on NADPH-diaphorase-containing myenteric neurones of rat ileum and proximal colon. Cell and tissue research, 279, 379-383. https://doi.org/10.1007/BF00318495

Bjørling-Poulsen, M., Andersen, H. R., \& Grandjean, P. (2008). Potential developmental neurotoxicity of pesticides used in Europe. Environmental Health, 7, 50. https://doi.org/10.1186/1476-069X-7-50

Bolognesi, C. (2003). Genotoxicity of pesticides: a review of human biomonitoring studies. Mutation Research/Reviews in Mutation Research, 543, 251-272. https://doi.org/10.1016/S1383-5742(03)00015-2 
Bongiovanni, B., De Lorenzi, P., Ferri, A., Konjuh, C., Rassetto, M., De Duffard, A. E., ... Duffard, R. (2007). Melatonin decreases the oxidative stress produced by 2, 4-dichlorophenoxyacetic acid in rat cerebellar granule cells. Neurotoxicity research, 11, 93. https://doi.org/10.1007/BF03033388

Bortolozzi, A. A., de Duffard, A. M. E., Duffard, R. O., \& Antonelli, M. C. (2004). Effects of 2, 4-dichlorophenoxyacetic acid exposure on dopamine D2-like receptors in rat brain. Neurotoxicology and teratology, 26, 599-605. https://doi.org/10.1016/j.ntt.2004.04.001

Boyer, L., Sidpra, D., Jevon, G., Buchan, A. M., \& Jacobson, K. (2007). Differential responses of VIPergic and nitrergic neurons in paediatric patients with Crohn's disease. Autonomic Neuroscience, 134, 106-114. https://doi.org/10.1016/j.autneu.2007.03.001

Bradberry, S. M., Watt, B. E., Proudfoot, A. T., \& Vale, J. A. (2000). Mechanisms of toxicity, clinical features, and management of acute chlorophenoxy herbicide poisoning: a review. Journal of Toxicology: Clinical Toxicology, 38, 111-122. https://doi.org/10.1081/CLT-100100925

Bukowska, B. (2003). Effects of 2, 4-D and its metabolite 2, 4-dichlorophenol on antioxidant enzymes and level of glutathione in human erythrocytes. Comparative Biochemistry and Physiology Part C: Toxicology \& Pharmacology, 135, 435-441. https://doi.org/10.1016/S1532-0456(03)00151-0

Bukowska, B., Głowacki, R., Michałowicz, J., Bald, E., \& Duda, W. (2008). The Effectiveness of Penetration of Erythrocyte Membrane by Sodium Salt of 2, 4-Dichlorophenoxyacetic Acid. Polish Journal of Environmental Studies, 17, 1.

Bukowska, B., Rychlik, B., Krokosz, A., \& Michałowicz, J. (2008). Phenoxyherbicides induce production of free radicals in human erythrocytes: oxidation of dichlorodihydrofluorescine and dihydrorhodamine 123 by 2, 4-D-Na and MCPA-Na. Food and Chemical Toxicology, 46, 359-367. https://doi.org/10.1016/j.fct.2007.08.011

Cameron, N. E., Cotter, M. A., \& Maxfield, E. K. (1993). Anti-oxidant treatment prevents the development of peripheral nerve dysfunction in streptozotocin-diabetic rats. Diabetologia, 36, 299-304. https://doi.org/10.1007/BF00400231

Charles, J. M., Bond, D. M., Jeffries, T. K., Yano, B. L., Stott, W. T., Johnson, K. A., ... Bus, J. S. (1996). Chronic dietary toxicity/oncogenicity studies on 2, 4-dichlorophenoxyacetic acid in rodents. Fundamental and applied toxicology, 33, 166-172. https://doi.org/10.1006/faat.1996.0154

Charles, J. M., Cunny, H. C., Wilson, R. D., \& Bus, J. S. (1996). Comparative subchronic studies on 2, 4-dichlorophenoxyacetic acid, amine, and ester in rats. Toxicological Sciences, 33, 161-165. https://doi.org/10.1093/toxsci/33.2.161

Correa, O. P., Mari, R. B., Toledo, E. L., Guimarães, J. P., Pereira, J. N. B., Germano, R. M., ... Stabille, S. R. (2017). Effects of the ingestion of 2, 4 Dichlorophenoxyacetic acidon jejunal myenteric neurons in rats. Journal of Morphological Sciences, 28. 
Cowen, T., Johnson, R. J. R., Soubeyre, V., \& Santer, R. M. (2000). Restricted diet rescues rat enteric motor neurones from age related cell death. Gut,47(5), 653-660. https://doi.org/10.1136/gut.47.5.653

Di Paolo, O., de Duffard, A. M. E., \& Duffard, R. (2001). In vivo and in vitro binding of 2, 4-dichlorophenoxyacetic acid to a rat liver mitochondrial protein. Chemico-biological interactions, 137(3), 229-241. https://doi.org/10.1016/S0009-2797(01)00255-1

Elo, H. A., \& MacDonald, E. (1989). Effects of 2, 4-dichlorophenoxyacetic acid (2, 4-D) on biogenic amines and their acidic metabolites in brain and cerebrospinal fluid of rats. Archives of toxicology, 63(2), 127-130. https://doi.org/10.1007/BF00316434

Fregonesi, C. E. P. T., Molinari, S. L., Alves, Â. M., Defani, M. A., Zanoni, J. N., Bazotte, R. B., \& De Miranda Neto, M. H. (2005). Morphoquantitative Aspects of Nitrergic Myoenteric Neurons from the Stomach of Diabetic Rats Supplemented with Acetyl-L-Carnitine. Anatomia, Histologia, $\quad$ Embryologia, 34, 93-97. https://doi.org/10.1111/j.1439-0264.2004.00578.x

Furness, J. B. (2006). The enteric nervous system (Vol. 13, p. 274). Malden, Mass.: Blackwell Pub.

Furness, J. B., \& Costa, M. (1987). The enteric nervous system. Churchill Livingstone.

Gabella, G. (1989). Fall in the number of myenteric neurons in aging guinea pigs. Gastroenterology, 96, 1487-1493. https://doi.org/10.1016/0016-5085(89)90516-7

Gagliardo, K. M., Clebis, N. K., Stabille, S. R., Mari, R. D. B., De Sousa, J. M. A., \& De Souza, R. R. (2008). Exercise reduces inhibitory neuroactivity and protects myenteric neurons from age-related neurodegeneration. Autonomic Neuroscience, 141(1-2), 31-37. https://doi.org/10.1016/j.autneu.2008.04.009

Greene E. C. (1963). Anatomy of the rat, Hafner Publishing Company, New York and London.

Hecker, B. R., Lake, C. L., DiFazio, C. A., Moscicki, J. C., \& Engle, J. S. (1983). The decrease of the minimum alveolar anesthetic concentration produced by sufentanil in rats. Anesthesia and analgesia,62(11), 987-990. https://doi.org/10.1213/00000539-198311000-00005

Hermes-Uliana, C., Pereira-Severi, L. S., Luerdes, R. B., Franco, C. L. M., Da Silva, A. V., de Almeida Araújo, E. J., \& Sant'Ana, D. D. M. G. (2011). Chronic infection with Toxoplasma gondii causes myenteric neuroplasticity of the jejunum in rats. Autonomic Neuroscience, 160, 3-8. https://doi.org/10.1016/j.autneu.2010.09.003

Johnson, R. J. R., Schemann, M., Santer, R. M., \& Cowen, T. (1998). The effects of age on the overall population and on subpopulations of myenteric neurons in the rat small intestine. Journal of anatomy, 192(4), 479-488. https://doi.org/10.1046/j.1469-7580.1998.19240479.x 
Konjuh, C., García, G., López, L., Evangelista de Duffard, A. M., Brusco, A., \& Duffard, R. (2008). Neonatal hypomyelination by the herbicide 2, 4-dichlorophenoxyacetic acid. Chemical and ultrastructural studies in rats. Toxicological sciences, 104, 332-340. https://doi.org/10.1093/toxsci/kfn085

Lomax, A. E., Fernandez, E., \& Sharkey, K. A. (2005). Plasticity of the enteric nervous system during intestinal inflammation. Neurogastroenterology \& Motility, 17, 4-15. https://doi.org/10.1111/j.1365-2982.2004.00607.x

Marese, A. C. M., de Freitas, P., \& Natali, M. R. M. (2007). Alterations of the number and the profile of myenteric neurons of Wistar rats promoted by age. Autonomic Neuroscience, 137, 10-18. https://doi.org/10.1016/j.autneu.2007.05.003

Margonato, F. B., Batista, M. R., dos Santos Silva, E. R., \& Baroni, E. A. (2003). Efeito do herbicida 2, 4-D (Ácido 2, 4-Diclorofenoxiacético) na morfologia e função renal de Ratos Wistar. Arquivos de Ciências da Saúde da UNIPAR, 7. https://doi.org/10.25110/arqsaude.v7i2.2003.1065

Mari, B. R., Clebis, N. K., Gagliardo, K. M., Guimarães, J. P., Stabille, S. R., De Mello Germano, R., \& De Souza, R. R. (2008). Effects of exercise on the morphology of the myenteric neurons of the duodenum of Wistar rats during the ageing process. Anatomia, Histologia, Embryologia, 37, 289-295. https://doi.org/10.1111/j.1439-0264.2008.00843.x

Mattson, J. L., Charles, J. M., Yano, B. L., Cunny, H. C., Wilson, R. D., \& Bus, J. S. (1997). Single-dose and chronic dietary neurotoxicity screening studies on 2, 4-dichlorophenoxyacetic acid in rats. Fundamental and Applied Toxicology, 40, 111-119. https://doi.org/10.1006/faat.1997.2361

Miranda-Neto, M. H., Molinari, S. L., Natali, M. R. M., \& Sant'Ana, D. D. M. G. (2001). Regional differences in the number and type of myenteric neurons of the ileum of rats: a comparison of techniques of the neuronal evidentiation. Arquivos de neuro-psiquiatria, 59, 54-59. https://doi.org/10.1590/S0004-282X2001000100012

Natali, M. R. M. (2003). Morphometry and quantification of the myenteric neurons of the duodenum of adult rats fed with hypoproteic chow. Int $J$ Morphol, 21, 273-277. https://doi.org/10.4067/S0717-95022003000400003

Natali, M. R. M., \& Miranda-Neto, M. H. (1996). Effect of maternal protein deprivation on morphological and quantitative aspects of the myenteric plexus neurons of proximal colon in rats. Arq Neuropsiquiatr, 54, 273-279. https://doi.org/10.1590/S0004-282X1996000200014

Natali, M. R. M., Molinari, S. L., Valentini, L. C., \& Neto, M. H. D. M. (2005). Morphoquantitative evaluation of the duodenal myenteric neuronal population in rats fed with hypoproteic ration. Biocell, 29, 39. https://doi.org/10.32604/biocell.2005.29.039

Palmeira, C. M., Moreno, A. J., Bairos, V., \& Madeira, V. M. (1997). Structural alterations in isolated hepatocytes induced by the herbicides paraquat, dinoseb and 2, 4-D. Medical science research, 25, 339-342. 
Paulino, C. A., Guerra, J. L., Oliveira, G. H., \& Palermo-Neto, J. (1996). Acute, subchronic and chronic 2, 4-dichlorophenoxyacetic acid (2, 4-D) intoxication in rats. Veterinary and human toxicology, 38, 348-352.

Phillips, R. J., \& Powley, T. L. (2001). As the gut ages: timetables for aging of innervation vary by organ in the Fischer 344 rat. Journal of comparative neurology, 434(3), 358-377. https://doi.org/10.1002/cne.1182

Phillips, R. J., \& Powley, T. L. (2007). Innervation of the gastrointestinal tract: patterns of aging. Autonomic Neuroscience, 136(1-2), 1-19. https://doi.org/10.1016/j.autneu.2007.04.005

Phillips, R. J., Kieffer, E. J., \& Powley, T. L. (2003). Aging of the myenteric plexus: neuronal loss is specific to cholinergic neurons. Autonomic Neuroscience, 106(2), 69-83. https://doi.org/10.1016/S1566-0702(03)00072-9

Rodrigues, B. N., \& de Almeida, F. S. (1998). Guia de herbicidas (pp. 137-142). Londrina: Iapar.

Rosso, S. B., Cáceres, A. O., de Duffard, A. M. E., Duffard, R. O., \& Quiroga, S. (2000). 2, 4-Dichlorophenoxyacetic acid disrupts the cytoskeleton and disorganizes the Golgi apparatus of cultured neurons. Toxicological sciences, 56, 133-140. https://doi.org/10.1093/toxsci/56.1.133

Sant'Ana, D. M., Araújo, E. J., Ramos, D. H., Hermes-Uliana, C., \& Natali, M. R. M. (2012). Characterization of the myenteric neuronal population and subpopulation of the duodenum of adult wistar rat fed with hypoproteic chow. Anais da Academia Brasileira de Ciências, 84, 799-806. https://doi.org/10.1590/S0001-37652012005000050

Scherer-Singler, U., Vincent, S. R., Kimura, H., \& McGeer, E. G. (1983). Demonstration of a unique population of neurons with NADPH-diaphorase histochemistry. Journal of neuroscience methods, 9, 229-234. https://doi.org/10.1016/0165-0270(83)90085-7

Schvartsman, C., \& Schvartsman, S. (1999). Intoxicações exógenas agudas. Jornal de Pediatria, 75, 244-250. https://doi.org/10.2223/JPED.394

Shotton, H. R., \& Lincoln, J. (2006). Diabetes only affects nitric oxide synthase-containing myenteric neurons that do not contain heme oxygenase 2 . Brain research, 1068, 248-256. https://doi.org/10.1016/j.brainres.2005.11.057

Shotton, H. R., Adams, A., \& Lincoln, J. (2007). Effect of aminoguanidine treatment on diabetes-induced changes in the myenteric plexus of rat ileum. Autonomic Neuroscience, 132(1-2), 16-26. https://doi.org/10.1016/j.autneu.2006.08.007

Silva Porto, G., Pereira, J. N. B., Tiburcio, V. G., Stabille, S. R., de Faria, H. G., de Melo Germano, R., \& de Britto Mari, R. (2012). Effect of caloric restriction on myenteric neuroplasticity in the rat duodenum during aging. Autonomic Neuroscience, 168, 43-47. https://doi.org/10.1016/j.autneu.2012.01.006

Soares, A., Schoffen, J. P. F., De Gouveia, E. M., \& Natali, M. R. M. (2006). Effects of the 


\section{Macrothink}

Journal of Agricultural Studies

ISSN 2166-0379

2021, Vol. 9, No. 1

neonatal treatment with monosodium glutamate on myenteric neurons and the intestine wall in the ileum of rats. Journal of gastroenterology, 41, 674. https://doi.org/10.1007/s00535-006-1839-5

Stürtz, N., Bongiovanni, B., Rassetto, M., Ferri, A., de Duffard, A. E., \& Duffard, R. (2006). Detection of 2, 4-dichlorophenoxyacetic acid in rat milk of dams exposed during lactation and milk analysis of their major components. Food and chemical toxicology, 44, 8-16. https://doi.org/10.1016/j.fct.2005.03.012

Tsman, S. (1991). Intoxicações agudas. São Paulo. p. 266-267.

Wester, T., O'Briain, D. S., \& Puri, P. (1999). Notable postnatal alterations in the myenteric plexus of normal human bowel. Gut, 44, 666-674. https://doi.org/10.1136/gut.44.5.666

Zanoni, J. N., Buttow, N. C., Bazotte, R. B., \& Neto, M. M. (2003). Evaluation of the population of NADPH-diaphorase-stained and myosin- $\mathrm{V}$ myenteric neurons in the ileum of chronically streptozotocin-diabetic rats treated with ascorbic acid. Autonomic Neuroscience, 104, 32-38. https://doi.org/10.1016/S1566-0702(02)00266-7

\section{Copyright Disclaimer}

Copyright for this article is retained by the author(s), with first publication rights granted to the journal.

This is an open-access article distributed under the terms and conditions of the Creative Commons Attribution license (http://creativecommons.org/licenses/by/4.0/). 